\title{
Growth response of Dendrocalamus asper on elevational variation and intra-clump spacing management
}

\author{
AQMAL NUR JIHAD, BUDIADI", WIDIYATNO \\ Department of Silviculture, Faculty of Forestry, Universitas Gadjah Mada. Jl. Agro No. 1, Bulaksumur, Sleman 55281, Yogy akarta, Indonesia. \\ Tel.: +62-274-512102, 6491420, Fax.: +62-274-550541, `email: budiadi@ugm.ac.id \\ Manuscript received: 24 June 2021. Revision accepted: 22 August 2021.
}

\begin{abstract}
Growth response of Dendrocalamus asper on elevational variation and intra-clump spacing management. 2021. Title. Biodiversitas 22: 3801-3810. Dendrocalamus asper (Schult. Schult. F.) Backer Ex. K. Heyne is a well-known commodity classified as a non-timber forest product (NTFP) to substitute wood-based products in the future. While bamboo is widely distributed in various habitats, and it could impact growth performance and quality. Nevertheless, the development of bamboo research on the upstream level is quite rare, specifically for clumping bamboo species. Therefore, our study aimed to reveal the performance in elevational variation and to discover the intra-clump spacing and diameter relationship. The elevational variation was divided into three levels, which were lower, middle, and higher levels. Each elevation was established in 9 plots with parameters observed were culm diameter at breast height $(\mathrm{DBH})$, culm height $(\mathrm{H})$, and culm volume $(\mathrm{V})$ of $D$. asper. The intra-clump spacing was used to assess the relationship between the clump density and diameter growth. The research is complemented with in-depth interviews to explore the traditional silvicultural practices of Dendrocalamus asper and spatial analysis to generate land surface temperature and soil moisture index. The result showed that there is no effect $(P>0.05)$ of elevational variation to $D$. asper growth and development, while the availability of intra-clump spacing showed a significant result $(P<0.05)$ on the culm DBH of $D$, asper. Furthermore, our result suggests a wider intra-clump spacing $\left(0.4-0.6 \mathrm{~m}^{2}\right)$ is more recommended than a narrow intra-clump spacing for optimal culm diameter growth. Additionally, bamboo plantation was still less managed and utilized. Therefore, improving the productivity of $D$. asper by maintaining plantation, i.e., fertilizing, managing spacing among clump bamboo, and harvesting to achieve sustainable development of the bamboo plantation is useful.
\end{abstract}

Keywords: Dendrocalamus asper, intra-clump spacing, elevational variation, silviculture of bamboo

\section{INTRODUCTION}

Bamboo is an important commodity that is classified as a non-timber forest product referred to as the material of building and industries in the future (Hossain et al. 2015; Kaur et al. 2016). Bamboo can contribute as an income resource of rural communities (Hogarth and Belcher 2013), carbon storage (Li et al. 2016; Liu and Yen 2021), and others ecosystem services (Muñoz-lópez et al. 2021). Globally, bamboo consists of 1,662 bamboo species, while the bamboo plantation was estimated to cover 35 million Ha around the world (Canavan et al. 2016; FAO 2020).

One of the popular bamboo species with various uses in Indonesian community forests is Dendrocalamus asper. Dendrocalamus asper (Schult. Schult. F.) Backer Ex. K. Heyne can be used as an option for wood-based products (Chaowana 2013). Furthermore, the wide range of bamboo benefits namely, copper absorber, rehabilitation and phytoremediation plant species, nutrient source, biomass sequestration, and to reduce soil erosion and nutrient leaching (Soejono et al. 2013; Nirmala et al. 2014; Chua et al. 2019; Durai and Long 2019; Go et al. 2019; Bian et al. 2020). Thus, the large scale of Bamboo (i.e. D. asper) could improve economic, social, and ecosystem services (Hogarth and Belcher 2013; Yuen et al. 2017; Ramakrishnan et al. 2018).

The distribution of $D$. asper ranged from lowland to upland (up to $2000 \mathrm{~m}$ asl./meter above sea level)
(Zulkarnaen 2015). Consequently, the variations among environmental factors may affect bamboo's growth, for instance, the emergence of bamboo shoots or culm, internode length, and diameter size (Banik 2015b). Besides, the adjustment of clump at the feasible quality and quantity influenced the growth of bamboo (Durai and Long 2019). Therefore, understanding the vertical and horizontal structure should be embedded in bamboo clump management to achieve effective bamboo sustainability management (Banik 2015b).

However, there is inadequate research intervention regarding the effect of environmental variations on $D$. asper growth and development. Previous studies showed that the study of bamboo was dominated by postharvest research during 1994-2019, i.e., tensile testing, strength properties, bending strength, physical and mechanical properties, several chemical compounds, post-harvest products (Nurhazwani et al. 2016; Srivaro and Jakranod 2016; Kadivar et al. 2019; Suryadi et al. 2019; Widodo et al. 2019). The growth of bamboo was affected by environmental factors i.e., altitude and temperature (Sonboon 2001) and clump density (Mera and Xu 2014). For instance, the growth of moso bamboo (Phyllostachys edulis) in elevation $1,400 \mathrm{~m}$ asl was higher than $1,000 \mathrm{~m}$ asl (Chen et al. 2014). Then, standing culm density would enhance shoot production and the growth of bamboo (Mera and Xu 2014; Bahru et al. 2021). 
Additionally, the habitat loss and intensive harvesting of bamboo could potentially place bamboo species on extinction threats (Hakim et al. 2002). Therefore, research on elevational variation and relationship of intra-clump spacing management and traditional silvicultural practices on bamboo growth and development is essential to improve the productivity of bamboo plantations. Our objectives were as follows: (i) revealing the performance of $D$. asper growth among elevational variation and intra-clump spacing and (ii) discovering the relationship between diameter and intra-clump spacing on $D$. asper.

\section{MATERIALS AND METHODS}

\section{Study area}

The research was conducted at Sleman District, Yogyakarta, Indonesia. The experimental site was established in a random mix planting pattern, whereas the bamboo plantation was relatively dominant in their community plantation. Accordingly, the random mix planting was not associated with specific species, while several valuable species according to community and market perspective were planted by the community, such as Paraserianthes falcataria; Artocarpus altilis; Leucaena leucocephala; Cocos nucifera, Gliricidia sepium, Gnetum gnemon, and other bamboo species.

The research site was located at $110^{\circ} 33^{\prime} 00^{\prime \prime}$ and $110^{\circ}$ $13^{\prime} 00^{\prime \prime} \mathrm{E}, 7^{\circ} 34^{\prime} 51^{\prime \prime}$ and $7^{\circ} 47^{\prime} 30^{\prime \prime} \mathrm{S}$. An average of 15 years annual precipitation of the area was up to 2758,47 mm per year (BMKG 2015, unpublished data). According to Sleman District official data (2021, unpublished data) total area of Sleman was 57.482 ha which was divided into
17 sub-districts. Based on topography, the southern side was relatively flat while the higher altitude would be found with the higher steep at northern side due to Mount Merapi. Furthermore, the altitude was vary, ranged from below 100 $\mathrm{m}$ asl. and above $1.000 \mathrm{~m}$ asl.

The field experiment was established with a randomized complete block design where the main plot was an elevational gradient. Accordingly, the research sites were distributed into three elevations, namely, lower elevation (<499 m asl.), medium elevation (500-999 m asl.), and higher elevation ( $>1,000 \mathrm{~m}$ asl.).

\section{Procedures}

Biometric data totaling 27 plots ( 9 plots per elevation, 1-2 clump per plot, and 227 culms on average) were collected to determine the number of parameters such as culm height $(\mathrm{H}, \mathrm{m})$, culm diameter at breast height $(\mathrm{DBH}$, $\mathrm{cm})$, culm volume $\left(\mathrm{m}^{3}\right)$, and intra-clump spacing $\left(\mathrm{m}^{2}\right)$. A total of 27 bamboo clumps were observed with an intraclump spacing that ranged between $0.0001 \mathrm{~m}^{2}$ to $0.6 \mathrm{~m}^{2}$. Measurement of intra-clump spacing approached by calculating of total area of the clump divided by the number of culms. However, these intra-clump spacing variations are non-operational values. To facilitate analysis, we conducted an experiment by classifying it into 3 classes of intra-clump spacing, which were mainly, narrow $(<0.19$ $\left.\mathrm{m}^{2}\right)$, intermediate $\left(0.2-0.39 \mathrm{~m}^{2}\right)$, and wide $\left(\geq 0.4 \mathrm{~m}^{2}\right)$. We gathered additional data, such as traditional silvicultural practices and environmental conditions (land surface temperature and soil moisture index) as complementary data. Ecological data was obtained from spatial analysis using Landsat-8 (path 120, row 65), which was acquired on May 20, 2020.

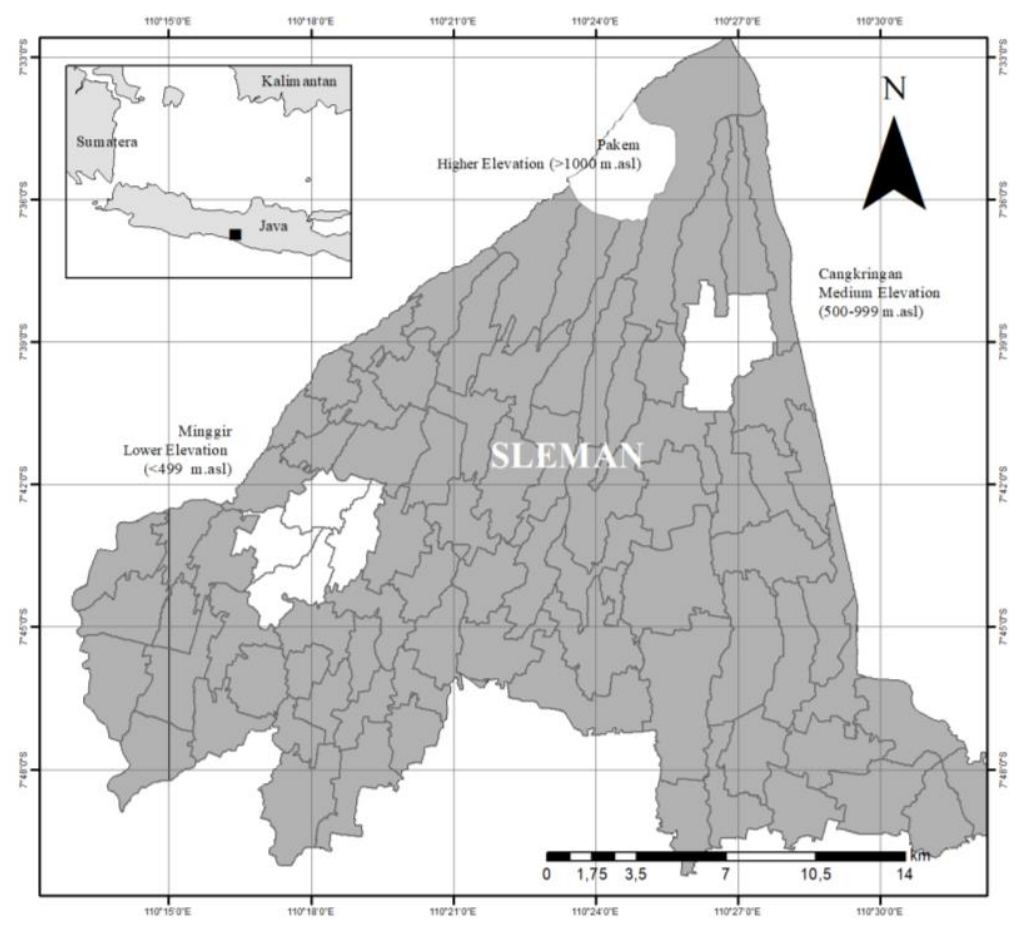

Figure 1. Location of the study area in Sleman District, Yogyakarta, Indonesia 


\section{Data analysis}

Diameter at breast height $(\mathrm{DBH}, \mathrm{cm})$ was the diameter of bamboo measured at $1.3 \mathrm{~m}$, and the culm height $(\mathrm{H}, \mathrm{m})$ was measured using Haga altimeter which is a tree height measuring tool based on the angle between altimeter position to the top in a certain length from the object. Mean while, the culm volume $\left(\mathrm{V}, \mathrm{m}^{3}\right)$ of each bamboo culm was calculated using the following formula:

$$
\begin{aligned}
\mathrm{V}_{\text {bamboo }} & =\mathrm{DBH}_{\text {culm }}{ }^{2}-\left(\mathrm{DBH}_{\text {culm }} * 0.7\right)^{2} / 4 * \pi * \mathrm{H}_{\text {length }} * \\
& \mathrm{~F}_{\text {bamboo }} \ldots \ldots \text { (1) }(\mathrm{MoEF} \text { and FAO 2007) }
\end{aligned}
$$

Where: DBH: Diameter(m); $\pi$ : 3.14; H: height (m); F: correction factor for bamboo $(0,8)$

Furthermore, the clump basal area was calculated following the formula:

$$
\mathrm{BA}=\pi *\left(\mathrm{DBH}_{\mathrm{clump}}\right)^{2} * 0.25
$$

Where: BA: basal area $\left(\mathrm{m}^{2}\right) ; \pi: 3.14$; $\mathrm{DBH}_{\text {clump }}$ : clump diameter $(\mathrm{m})$.

The data were analyzed using SAS v.9.0 software using analysis of variance (ANOVA). Suppose the result indicates that there is no significant effect of elevational variation on growth and development of bamboo clumps. Here the analysis is continued separately, and elevational variation is no longer used as a variable in the second ANOVA analysis stage to test the effect of the available intra-clump spacing classes. The difference between treatments was analyzed using a Duncan Multiple Range Test (DMRT) at a significance level of 5\%. Regression analysis was conducted to determine the relationship between intra-clump spacing and culm DBH. Diameter is a critical parameter in assessing the effectiveness of intraclump spacing in a clump, so that the regression analysis was performed on diameter.

The analysis of supporting data related to environmental data, both temperature, and soil moisture, was carried out with the spatial analysis of Landsat-8, which was equipped with a thermal sensor. The land surface temperature and soil moisture index data obtained were used as materials for correlating analysis on the three variables, namely height, diameter, and volume. The channel bases used in image processing include channel 4, channel 5, channel 10, and channel 11. Soil moisture index (SMI) data was based on the relationship between land surface temperature (LST) and the normalized vegetation index (NDVI). The number of equations in the analysis refers to Potic et al. (2017) cited by Tajudin et al. (2021), as follows:

$$
\text { SMI: (LST } \left.{ }_{\text {max }}-\mathrm{LST}\right) /\left(\mathrm{LST}_{\text {max }}-\mathrm{LST}_{\text {min }}\right)
$$

Where LST is land surface temperature, while maximum LST and minimum LST were obtained from NDVI data through this formula:

$$
\begin{aligned}
& L S T_{\max }=\mathrm{a}_{1} * \mathrm{NDVI}+\mathrm{b}_{1} \\
& L S T_{\text {min }}=\mathrm{a}_{2} * \mathrm{NDVI}+\mathrm{b}_{2}
\end{aligned}
$$

Where $a_{1}, a_{2}, b_{1}$, dan $b_{2}$ are empirical parameters. There are two required parameters, namely, LST and NDVI. And LST was obtained from the following equation:

$$
\mathrm{LST}=\mathrm{Tb} /(1+(\lambda * \mathrm{~Tb} / \mathrm{c} 2) * \ln (\mathrm{e}))
$$

$\mathrm{Tb}$ is satellite brightness temperature, $\lambda$ is the wavelength of emitted radiance, $\mathrm{c} 2=1.4388 * 10^{-2} \mathrm{~m} \mathrm{~K}$ and $\mathrm{e}=$ emissivity (typically 0.95 ). Tb was obtained from the following equation:

$$
\mathrm{Tb}=(\mathrm{K} 2 / \mathrm{Ln}(\mathrm{K} 1 * \mathrm{e} / \mathrm{L}+1))
$$

The values of $\mathrm{K}$ and $\mathrm{L}$ were constants obtained from sensors and conversion calculations for each metadata file Landsat 8. Meanwhile, to obtain NDVI data was obtained through the following equation:

$$
\mathrm{NDVI}=(\mathrm{NIR}-\mathrm{Red}) /(\mathrm{NIR}+\mathrm{red})
$$

Where the NIR and Red values are derived from channels 4 and 5, SMI data obtained would range from 0 to 1 , which can be interpreted as 0 for areas with low humidity and 1 for areas with high humidity and tend to be wet.

\section{The status of traditional bamboo silvicultural practices}

In this study, traditional silvicultural practices refer to how the community manages or treats the $D$. asper clumps. Traditional bamboo management can be grouped into several aspects: land preparation, planting, maintenance, pest control, and harvesting (Irawan et al. 2019).

Traditional silvicultural practices were obtained through in-depth interviews with 15 key-informant persons, dominated by bamboo clump owners. Key-informant person criteria include (i) full enculturation, (ii) involvement, (iii) availability of time, (iv) neutrality, and (v) readiness to provide information (Spradley 2007).

Inteview on traditional silviculture encompasses the stages of traditional bamboo management by the owners. The results of in-depth interviews were analyzed through several stages such as data reduction, thematic connection, and data interpretation (Seidman 2015).

Overall, in-depth interview was conducted to create narrative (Bariyah 2020), thus the qualitative analysis synthesizes the complete figure of traditional silvicultural practices of $D$. asper applied by the community based on the results of interviews. Furthermore, the output of the qualitative analysis found that the traditional $D$. asper clump management cycle was a closed cycle.

\section{RESULTS AND DISCUSSION}

\section{The effect of elevational variation and intra-clump spacing to $D$. asper growth}

Spatial analysis from Landsat- 8 showed that research sites have different environmental conditions. The higher temperature was found on the southern side, which has a lower elevation, while the SMI shows the highest value on the northern side. This significant difference was shown in 
Figures 2 and 3, either temperature $(P<0.05)$ or SMI $(P<$ $0.05)$ due to the difference in altitude. The temperatures in the lower, medium, and higher elevations were $21.39^{\circ} \mathrm{C}$, $20.22^{\circ} \mathrm{C}$, and $18.51^{\circ} \mathrm{C}$, respectively, while the SMI in the low, medium, and highlands is $0.21,0.26$, and 0.34 .

Our result elucidated that the elevational variation of bamboo's site plantation does not affect the culm height, culm diameter, and volume per individual of $D$. asper culm diameter $(P>0.05$, Table 1$)$. The culm height of $D$. asper in the lower, medium, and higher elevation was $17.28 \pm$
$0.99 \mathrm{~m}, 16.38 \pm 2.53 \mathrm{~m}, 15.42 \pm 3.7 \mathrm{~m}$, respectively (Figure 4.A). A similar pattern was shown on the culm diameter and culm volume, as follows, DBH of $D$. asper in the lower, medium, and higher elevation was $13.92 \pm 1.39$ $\mathrm{cm}, 13.8 \pm 1.65 \mathrm{~cm}$, and $12.4 \pm 3.92 \mathrm{~cm}$, respectively (Figure 4.B). Meanwhile, the average culm volume per individual of $D$. asper in the lower, medium, and higher elevation was $0.124 \pm 0.02 \mathrm{~m}^{3}, 0.106 \pm 0.03 \mathrm{~m}^{3}$, and 0.102 $\pm 0.06 \mathrm{~m}^{3}$, respectively (Figure $4 . \mathrm{C}$ ).

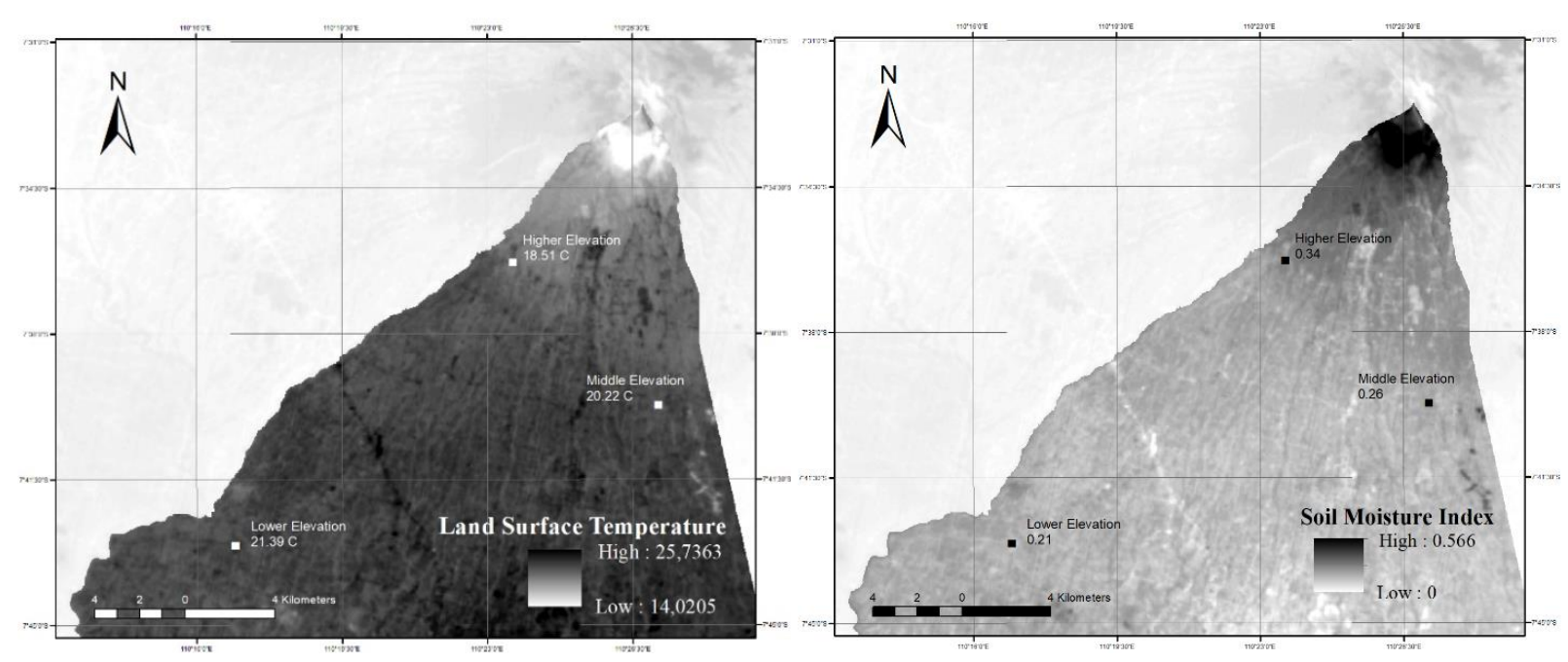

Figure 2. Land Surface Temperature (LST) and Soil Moisture Index (SMI) at Sleman District generated by Landsat 8.
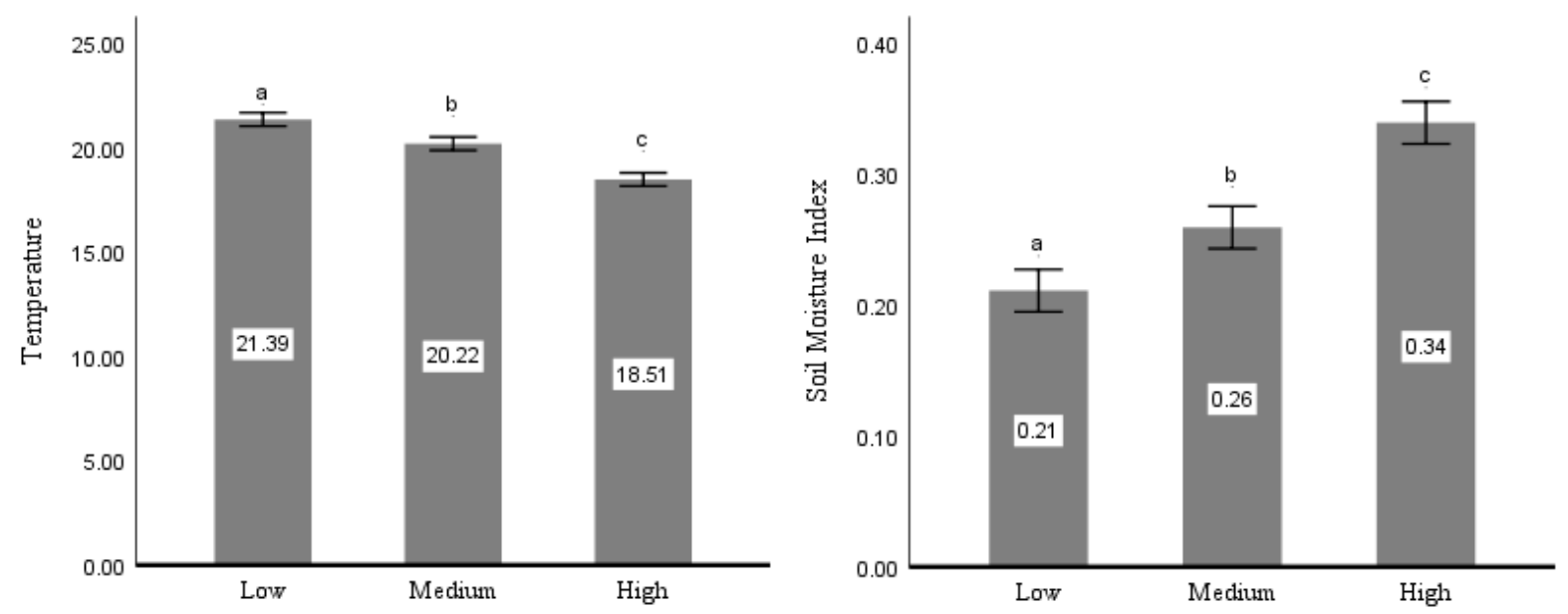

Figure 3. The average temperature and soil moisture index based on elevational variation

Table 1. Influence of elevation on Dendrocalamus asper growth

\begin{tabular}{lccccccc}
\hline \multirow{2}{*}{ Source } & \multirow{2}{*}{ df } & \multicolumn{3}{c}{ Mean square } & \multicolumn{3}{c}{ F value } \\
\cline { 2 - 8 } & & Height & DBH & Vol & Height & DBH & Vol \\
\hline Replication & 7 & 13.44 & 9.33 & 0.0028 & 3.52 & 1.74 & 1.89 \\
Elevation & 2 & 6.95 & 6.27 & 0.0007 & $1.82 \mathrm{~ns}$ & $1.17 \mathrm{~ns}$ & $0.49 \mathrm{~ns}$ \\
\hline
\end{tabular}

Note: ns: no significant difference among treatments at t $\alpha 0.05$ 


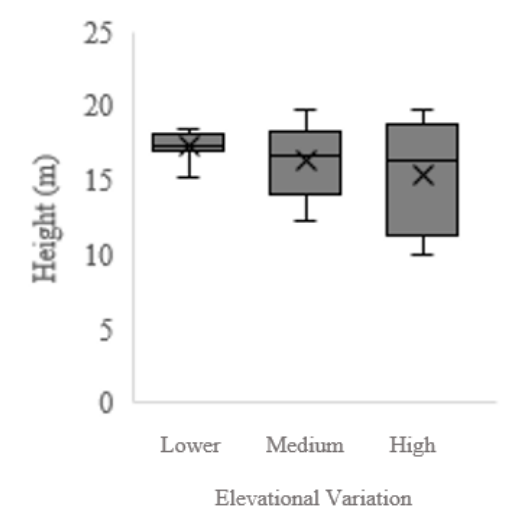

A

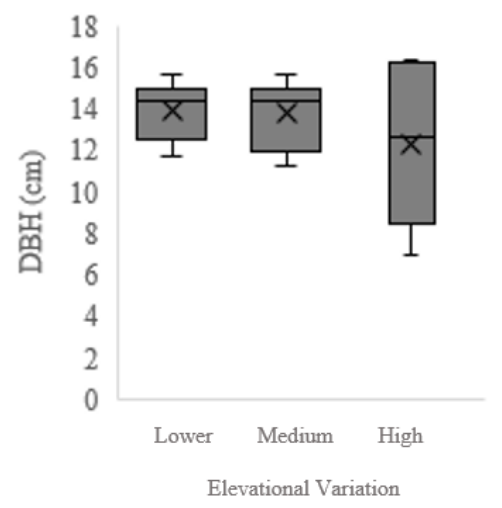

B

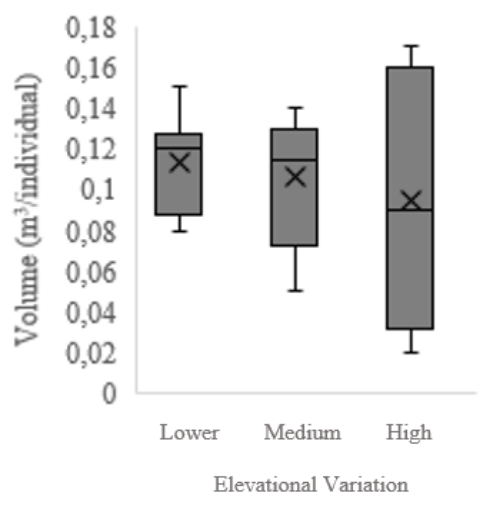

C

Figure 4. The average A. culm height, B. culm diameter (DBH), and C. culm volume of Dendrocalamus asper culms in elevational variation.

Table 2. Correlation analysis between environmental factors and Dendrocalamus asper growth

\begin{tabular}{llll}
\hline \multirow{2}{*}{ Variables } & \multicolumn{3}{c}{ Pearson correlation } \\
\cline { 2 - 4 } & Height & \multicolumn{1}{c}{ Diameter } & \multicolumn{1}{c}{ Volume } \\
\hline Land Surface Temperature & $0.107 \mathrm{~ns}$ & $0.154 \mathrm{~ns}$ & $0.314 \mathrm{~ns}$ \\
Soil Moisture Index & $0.107 \mathrm{~ns}$ & $0.15 \mathrm{~ns}$ & $0.3 \mathrm{~ns}$ \\
\hline
\end{tabular}

Note: ns: no significant difference among treatments at t $\alpha 0.05$

Our result showed that $D$. asper in the lower elevation has a greater average than higher elevation due to a various standard deviation value at higher elevation, in height, culm diameter, and volume parameters. The culm height ranges from $10 \mathrm{~m}$ to $20 \mathrm{~m}$, while the diameter ranges from $8 \mathrm{~cm}-17 \mathrm{~cm}$. As a consequence, the volume was also affected due to the formulation consisting of these two parameters. In contrast, lower and medium elevations showed a narrow standard deviation on the bamboo's culm height, culm diameter, and culm volume. It suggested that optimal growth of $D$. asper was in elevation below $999 \mathrm{~m}$ asl. temperatures above $20^{\circ} \mathrm{C}$.

Furthermore, temperature, rainfall, and soil properties could influence the distribution and growth of bamboo (Mera and Xu 2014; Xie et al. 2019). Nonetheless, our research showed no correlation between LST and SMI to height, diameter, and volume of $D$. asper (Table 2). It was due to that the distribution of $D$. asper is quite wide range distribution and can grow at various sites with different environmental factors (Table 1). Our result strengthens that the elevational variation is still providing good growth of D. asper, which is still acceptable for the future development of the bamboo plantations. The result is quite different from previous research, which stated that the high temperature could stimulate growth and low temperature would inhibit the growth (Banik 2016). Several research proved that elevational variation would affect bamboo growth and the lower elevation provide a greater growth rate on Yushania alpina (Hoek et al. 2019) and Chusquea (Clark et al. 2015). In addition, according to various species of bamboo, each species has a favorable environmental requirement, such as Chimonobambusa utilis which is optimum on 1.500-2.000 m asl. (Li et al. 2014).

\section{Intra-clump spacing-diameter relationship}

Additionally, due to the insignificant result of the first analysis, elevation is no longer used as a variable. Consequently, we conduct ANOVA separately to examine the effect of intra-clump spacing to bamboo growth as complementary data for regression analysis. Figure 5 depicts the diameter distribution that can be grouped into three clusters written with Zone I to III notations. In Zone I, it can be seen that the diameter distribution is clustered with a relatively lower diameter. Zone II and Zone III have a larger diameter; however, the polynomial trend line shows an increasing value and reaches a peak of $0.41 \mathrm{~m}^{2}$ $0.6 \mathrm{~m}^{2}$ and then decreases. The three clusters should be the basis for determining silvicultural practices applied in community practices.

The diameter class for $D$. asper was based on market standards. The sizes of the diameter range from grade 1 to 4 were $0-9.99 \mathrm{~cm}, 10-13.99 \mathrm{~cm}, 14-16.99 \mathrm{~cm}$, and more than $17 \mathrm{~cm}$, respectively. Grade 1 is often referred to as apus (Gigantochloa apus) grade, while grade 4 is also mentioned as a super grade (Marzuni 2020, pers.com.). In Figure 6 , it can be seen that a wider intra-clump spacing has a relatively larger diameter performance. It can be shown that the intermediate and wide spaces were dominated by diameter class 3 accounted for $53 \%$ and $68 \%$, respectively. However, the polynomial regression shows that the average diameter increase in class 3 is in the 0.3-0.6 $\mathrm{m}^{2}$ intra-clump spacing and decreases after reaching an intra-clump spacing of more than $0.6 \mathrm{~m}^{2}$. These results indicate that the optimal point for diameter development of $D$. asper is estimated at nearly $0.4 \mathrm{~m}^{2}$ intraclump spacing or Zone II (Figure 5).

Furthermore, based on Figure 5 we compose several suggestions on each cluster as follows. Zone I, as a representation of the narrow intra-clump spacing requires (i) thinning to increase intra-clump spacing availability, (ii) improving soil quality with organic matters, and (iii) promoting qualified $D$. asper shoot or natural regeneration. Zone II which is the desired clusters should tend and manage the $D$. asper clump harvesting to achieve sustainability. Zone 3, despite having sufficient intra-clump spacing, requires management for effective bamboo clump 
management, by limiting clump expansion or creating new clump that is potentially more valuable than a single clump that is too wide.

ANOVA analysis of intra-clump spacing variation resulting significantly in diameter growth $(P<0.05$, Figure 7.A), however, the Intra-clump spacing variation didn't affect the height and volume of bamboo $(P>0.05$, Figure 7.B, C). The narrow intra-clump spacing has a lower value of diameter and volume, vice versa. The diameter of $D$. asper on narrow to wide, was $9.75 \pm 1.91 \mathrm{~cm}, 13.41 \pm 1.38$ $\mathrm{cm}$, and $15.4 \pm 0.85 \mathrm{~cm}$. Following that, the height and volume of $D$. asper were not significant. The culm height on narrow to wide value was $16.30 \pm 2.99 \mathrm{~m}, 16.64 \pm 0.75$ $\mathrm{m}$, and $15.35 \pm 4.03 \mathrm{~m}$, respectively. Its similar pattern is shown on culm volume as follows, $0.1 \pm 0.04 \mathrm{~m}^{3}, 0.11 \pm$ $0.02 \mathrm{~m}^{3}$, and $0.09 \pm 0.06 \mathrm{~m}^{3}$, respectively.

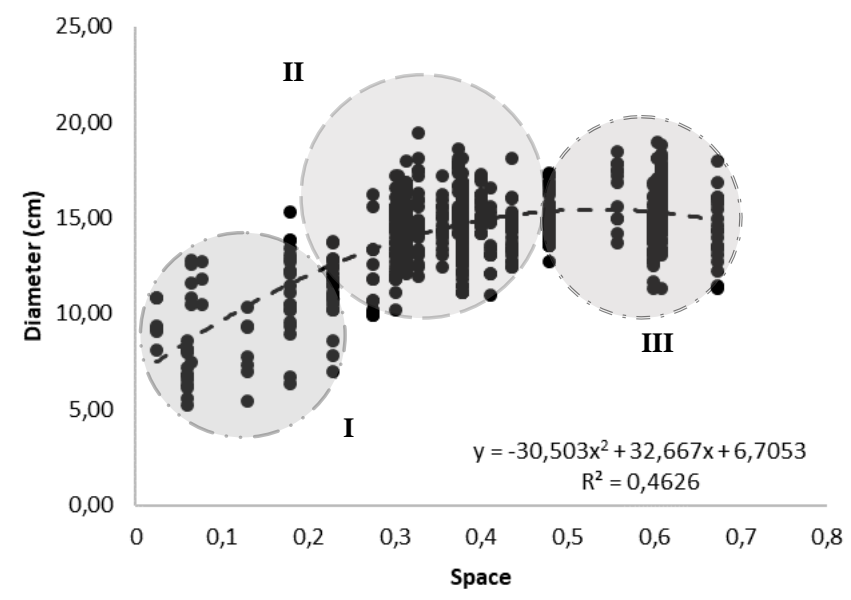

Figure 5. Diameter distribution based on intra-clump spacing within research sites.
On the scope of intra-clump spacing, according to Bahru and Ding (2020), clump density has implications for several parameters, such as bamboo shoot production to the diameter size of $D$. brandisii. Furthermore, the growing space within clumps influences the growth and yield (Raveendran et al. 2010; Mera and Xu 2014). A bigger diameter emerges due to resource availability and competition among the culms (Banik 2015a). In addition, there was positive correlation between culm diameter and culm height on Phyllotachy pubescens (Yen 2016). Intraclump density was one of bamboo stand structure parameters which varies across clumping bamboo species. Yet, intra-clump density is necessary for optimum and sustainable yield through retaining a reasonable number of the clump (Durai and Long 2019).

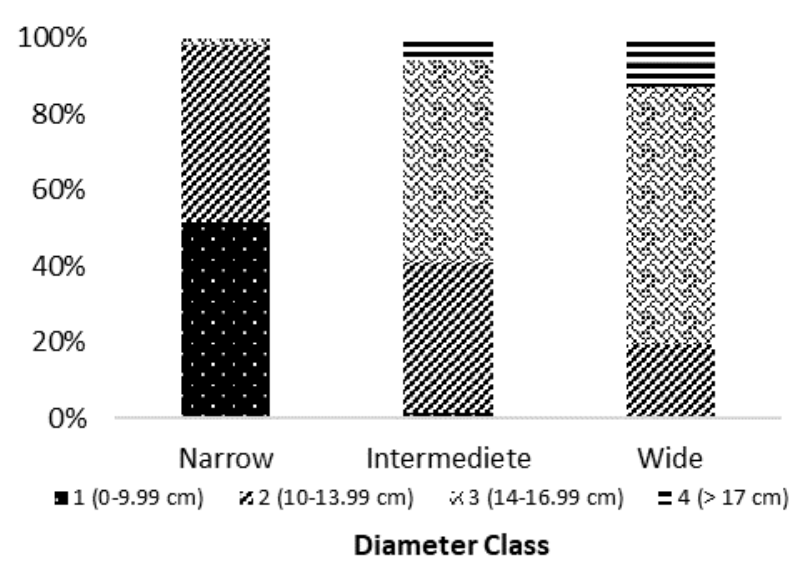

Figure 6. Proportion of culm diameter class in each intra-clump spacing variation
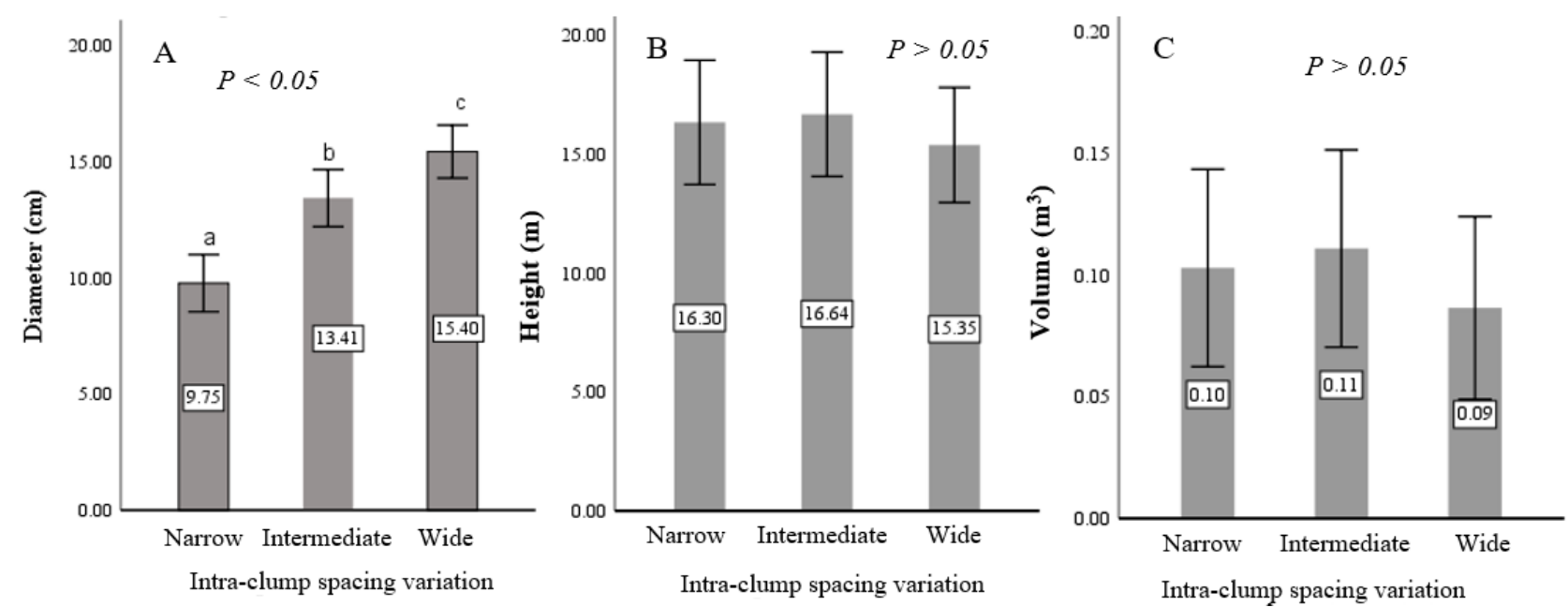

Figure 7. A. The average height, B. Diameter, and C. Volume of Dendrocalamus asper culms in intra-clump spacing variation 
Our result stimulates the need for the application of silviculture to $D$. asper in Indonesia. According to Banik (2015a) silvicultural knowledge is essential to production and sustainability. Through silviculture, the clump will be managed sustainably and could achieve higher production of bamboo. The silviculture of bamboo positively has affect, for instance, increases the culm recruitment, alleviates the mortality of young shoot, and raises the diameter and height trend (Mulatu and Fetene 2013). Meanwhile, space availability needs an adjustment due to the implication of overcutting or clear-cutting methods that issue a problem (Virtucio and Tomboc (1994) cited in Bahru and Ding 2020). Higher harvesting intensity affects culm recruitment in D. hamiltonii (Banik 2016; Darabant et al. 2016; Bahru and Ding 2020). Although the harvesting treatment would provide more space for new shoots, the emergence of new culm did not occur due to the absence of mother culm. Furthermore, the low number of mothers culm due to higher harvesting intensity causes a reduced nutrient supply to the young generation (Virtucio and Tomboc (1994) cited in Bahru and Ding 2020). It suggested that an intensification of bamboo plantation level should be maintained to increase the bamboo quality, although the intensive management provides both positive and negative impacts on soil properties, such as (i) stimulating root development, growth, and biomass; and (ii) decreasing soil nutrient (Ni et al. 2021).

\section{The implication to silviculture and conservation purposes of bamboo in Java}

Management of $D$. asper clumps in community forest considered as a traditional treatment. In-depth interview results explained that the traditional silvicultural practices form closed-cycle, which was distinguished into two stages (Figure 8). The first phase would occur in 0-5 years, and the second would resume the next year until reach the regenerative period. The letter notation in the closed-cycle in the second phase shows a number of activities in one year carried out by the community, such as clump maintenance, selection of young shoots or culms to be harvested and retained. In this cycle, the community can obtain vegetative material for regeneration through vegetative propagation, while generative propagation is carried out when the bamboo reaches the regenerative phase.

The two phases have different treatment emphases based on the main activity on the $D$. asper clump. The first phase tends to emphasize the management of individuals or culms, while the second phase leads to the management of the clump. This is due to the small number of clumps in the first five years of growth of $D$. asper. The treatments in the first phase included (i) fertilization before planting, (ii) pruning of the first generation of culm, and (iii) cutting of small branches. On the other hand, in the first phase, no harvesting was carried out, and the priority was on the emergence of new shoots.

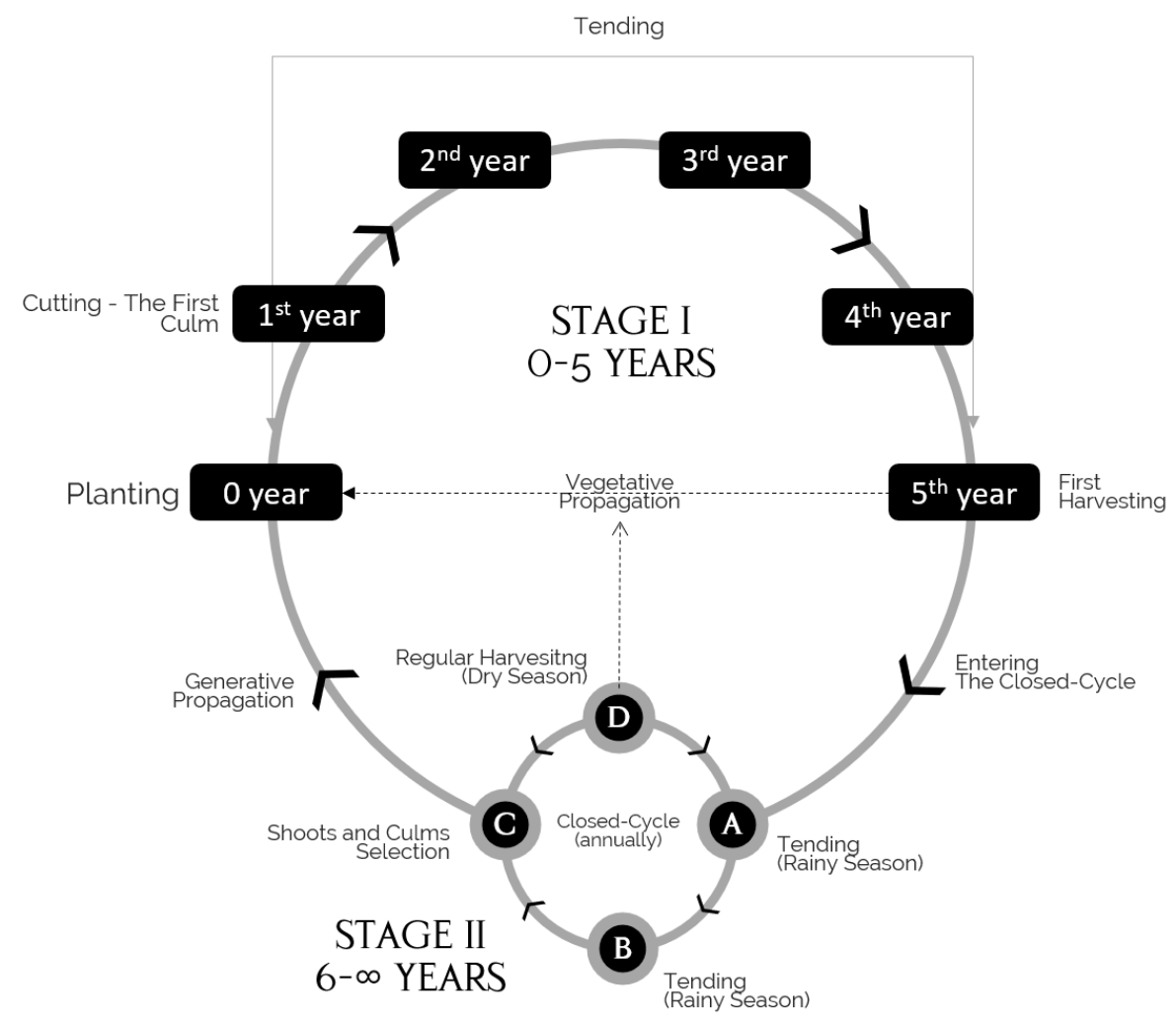

Figure 8. Dendrocalamus asper rotation system at the community forest, Sleman District, Indonesia 
After the clump reaches 5 years old, the $D$. asper begins harvesting period and entering the second stage which is closed-cycle. Several treatments were aimed at clump maintenance and harvest regulation to obtain sustainable bamboo clump management. Key treatments in the second stage included clump maintenance such as (i) clump cleaning, (ii) selective harvesting of culms and shoots, and (iii) relocation of litterfall into the clump. Those are important because young culms and litterfall have a contribution in provisioning the nutrients and maintain the rhizome system, which could positively affect shoot production and growth (Banik 2015b; Toledo-Bruno et al. 2017). Meanwhile, during regeneration, the community considers vegetative propagation due to long period of generative phase.

Traditional bamboo management is playing important role to achieve sustainability of production. According to our result, Sleman community with their local knowledge has tended to proper bamboo management which has closed-cycle in clump management. Whilst, Indonesia has a diverse local knowledge of bamboo either bamboo management or utilization that very important in further bamboo development for instance, age determination in order to seasonal and phenological indicators (Partasasmita et al. 2017); bamboo management in the mixed garden by Naga communities that include seedling propagation, land preparation, planting, maintenance, pest control, and harvesting (Irawan et al. 2019); Palembahan concept (human and environment relation) on bamboo forest management (Yeny et al. 2016). In addition, the traditional practices by community need attention either in relation to overcutting on harvesting system which would threaten the ecosystem (Das et al. 2016) or supporting policy that could provide more opportunities in the future.

The development of bamboo that goes comprehensively will have positive implications in supporting land restoration, the rejuvenation of the national economy, and combating climate change (Choudhury et al. 2012; Dwivedi et al. 2019; Ferreira et al. 2020; Singh et al. 2020). Bamboo-based agroforestry is an agroforestry system that is still rarely practiced, yet promising system and increase in trend by combining several commodities (Banik 2015a; Kittur et al. 2016; Hani 2020). The silviculture of bamboo also has a role in the conservation purposes, such as maintaining more culm to increase the function of erosion control function (Durai and Long 2019). The huge benefit from bamboo plantation would impact the awareness of the community, as the result, we could avoid bamboo extinction due to human population. On the other hand, we could also control bamboo expansion due to ecological risks that potentially emerged (Buziquia et al. 2019; Xu et al. 2020).

In conclusion, the elevational variation, soil temperature, and humidity had no effect on the growth of $D$. asper, whereas intra-clump spacing would affect the diameter growth of $D$. asper. Thus, increasing the productivity of bamboo plantations could be managed by increasing the intra-clump spacing of bamboo in a clump ranged 0.3-0.4 $\mathrm{m}^{2}$ and maintaining bamboo clump, i.e., harvesting and adjusting the intra-clump spacing of bamboo regeneration. The findings in this study are necessary to improve the traditional silvicultural practices of $D$. asper to achieve sustainability of bamboo plantations. Further research on D. asper and other sympodial bamboo is also necessary to enriching database for future decision support.

\section{ACKNOWLEDGEMENTS}

This research was supported by Universitas Gadjah Mada within the Final Project Recognition Program batch 2020. The authors would thank Sleman's bamboo association, Musimin, Eko, and Marzuni as the Forest Farmer Group leader on each study site. The authors also thank for data field team who support us in collecting data during social restrictions due to COVID-19 pandemic.

\section{REFERENCES}

Bahru T, Ding Y. 2020. Effects of thinning intensity and growth parameters on Dendrocalamus brandisii (Munro) Kurz shoot production in Simao District, Yunnan Province, Southwestern China. Glob Ecol Conserv 22: e00954. DOI: 10.1016/j.gecco.2020.e00954.

Bahru T, Liu G, Ding Y. 2021. Effects of standing culm density and fertilizer regimes on Dendrocalamus brandisii (Munro) Kurz shoot production at Simao District, Southwestern China. Trees, For. People 4 (November 2020): 100071. DOI: 10.1016/j.tfp.2021.100071.

Banik RL. 2015a. Bamboo silviculture. In: Liese W, Köhl M (eds.). Bamboo, The Plant and its Uses. Springer, Cham. DOI: 10.1007/9783-319-14133-6.

Banik RL. 2015b. Growth, behaviour and silviculture of bamboos. In: Kaushik S, Singh YP, Kumar D, Thapliyal M, Barthwal S (eds.) Bamboos in India. ENVIS Centre on Forestry, Dehradun.

Banik RL. 2016. Silviculture of South Asian Priority Bamboos. Springer, Cham.

Bariyah N. 2020. Developing a model of employment creation in border region: gaharu cultivation and honey bee farming in Bengkayang, West Kalimantan, Indonesia. Biodiversitas 21 (11): 5237-47. DOI: 10.13057/biodiv/d211127.

Bian F, Zhong Z, Zhang X, Yang C, Gai X. 2020. Bamboo-an untapped plant resource for the phytoremediation of heavy metal contaminated soils. Chemosphere 246. DOI: 10.1016/j.chemosphere.2019.125750.

Buziquia ST, Lopes PVF, Almeida AK, de Almeida IK. 2019. Impacts of bamboo spreading: a review. Biodivers Conserv 28 (14): 3695-3711. DOI: 10.1007/s10531-019-01875-9.

Canavan S, Richardson DM, Visser V, Le Roux JJ, Vorontsova MS, Wilson JRU. 2016. The global distribution of bamboos: assessing correlates of introduction and invasion. AoB Plants 9 (1): 1-18. DOI: 10.1093/aobpla/plw078. DOI: 10.1093/aobpla/plw078.

Chaowana P. 2013. Bamboo: An alternative raw material for wood and wood-based composites. J Mater Sci Res 2 (2): 90-102. DOI: 10.5539/jmsr.v2n2p90.

Chen TH, Chiu CY, Xie ZY, Wang S. 2014. Growth characteristics of moso bamboo (Phyllostachys pubescens) plantations at various altitudes-for instance in Daan Area, Nantou County. J Chinese For 47 (2):181-192.

Choudhury D, Sahu JK, Sharma GD. 2012. Value addition to bamboo shoots: a review. J Food Sci Technol 49 (4): 407-414. DOI: 10.1007/s13197-011-0379-z.

Chua J, Banua JM, Arcilla I, Orbecido A, de Castro ME, Ledesma N, Deocaris C, Madrazo C, Belo L. 2019. Phytoremediation potential and copper uptake kinetics of philippine bamboo species in copper contaminated substrate. Heliyon 5 (9): 1-9. DOI: 10.1016/j.heliyon.2019.e02440.

Clark LG, London X, Ruiz-Sanchez E. 2015. Bamboo taxonomy and habitat. In: Liese W, Köhl M (eds.). Bamboo, The Plant and its Uses. Springer, Cham. DOI: 10.1007/978-3-319-14133-6. 
Darabant A, Rai PB, Staudhammer CL, Dorji T. 2016. Designing and Evaluating Bamboo Harvesting Methods for Local Needs: Integrating Local Ecological Knowledge and Science. Environ Manage 58 (2): 312-22. DOI: 10.1007/s00267-016-0702-6.

Das MC, Nath AJ, Das AK. 2016. Indigenous traditional knowledge in conservation and management of bamboos of Barak Valley, Assam. J Tradit Folk Pract 2 (1): 185-92.

Durai J, Long TT. 2019. Manual for Sustainable Management of Clumping Bamboo Forest The International Bamboo and Rattan Organisation. INBAR, Beijing.

Dwivedi AK, Kumar A, Baredar P, Prakash O. 2019. Bamboo as a complementary crop to address climate change and livelihoodsinsights from India. For Pol Econ 102: 66-74. DOI: 10.1016/j.forpol.2019.02.007.

FAO. 2020. Global Forest Resources Assessment. FAO, Rome. DOI: $10.4324 / 9781315184487-1$

Seidman I. 2015. Interviewing as Qualitative Research. Teachers College Press, New York.

Ferreira E, Kalliola R, Ruokolainen K. 2020. Bamboo, climate change and forest use: a critical combination for Southwestern Amazonian Forests? Ambio 49 (8): 1353-63. DOI: 10.1007/s13280-019-01299-3.

Go JLC, Madrazo CF, Orbecido AH, de Castro MEG, Belo LP. 2019. Copper uptake potential of Philippine Giant Bamboo (Dendrocalamus asper) under varied initial copper concentration, Water Hardness and PH. MATEC Web Conf 268: 06005. DOI 10.1051/matecconf/201926806005.

Hakim L, Nakagoshi N, Isagi Y. 2002. Conservation ecology of Gigantochloa manggong: an endemic bamboo at Java, Indonesia. J Intl Dev Coop 9: 1-16.

Hani A. 2020. Dendrocalamus asper productivity after beginning thinning. IOP Conf Ser: Earth Environ Sci 449: 012007. DOI: 10.1088/1755-1315/449/1/012007.

Hoek Y Van Der, Emmanuel F, Eckardt W, Kwizera I, Derhé M. 2019. Recent decline in vegetative regeneration of bamboo (Yushania alpina), a key food plant for primates in Volcanoes National. Nature 9 (13041): 1-10. DOI: 10.1038/s41598-019-49519-w.

Hogarth NJ, Belcher B. 2013. The contribution of bamboo to household income and rural livelihoods in a poor and mountainous county in Guangxi, China Intl For Rev 15 (1) : 71-78

Hossain MF, Islam MA, Numan SM. 2015. Multipurpose uses of bamboo plants: a review. Intl Res J BiologicalSci 4 (12):57-60. DOI: $10.1505 / 146554813805927237$

Irawan B, Partasasmita R, Rahayu N, Setiawati T, Iskandar J. 2019. Indigenous knowledge of bamboos by Naga Community, Tasikmalaya District, West Java, Indonesia. Biodiversitas 20 (5) 1423-34. DOI: 10.13057/biodiv/d200535.

Kadivar M, Gauss C, Mármol G, de Sá AD, Fioroni C, Ghavami K, Savastano H. 2019. The influence of the initial moisture content on densification process of $D$. asper bamboo: physical-chemical and bending characterization. Constr Build Mater 229: 116896. DOI: 10.1016/j.conbuildmat.2019.116896.

Kaur PJ, Pant KK, Satya S, Naik SN. 2016. Bamboo: The Material of Future. Intl J Ser Multidiscip Res 2 (2): 27-34. DOI: 10.1000/ijsmr.v2i2.51.

Kittur BH, Sudhakara K, Mohan Kumar B, Kunhamu TK, Sureshkumar P. 2016. Bamboo based agroforestry systems in Kerala, India: performance of turmeric (Curcuma longa L.) in the subcanopy of differentially spaced seven-year-old bamboo stand. Agrofor Syst 90 (2): 237-50. DOI: 10.1007/s10457-015-9849-z.

Li LE, Lin YJ, Yen TM. 2016. Using allometric models to predict the aboveground biomass of thorny bamboo (Bambusa stenostachya) and estimate its carbon storage. Taiwan J For Sci 31 (1): 37-47.

Li Q-Y, Zhang Z-W, Tao J-P, Liu J-H, Yong X-H, Meng X-F, Li Z, Wang Y-J. 2014. Effect of elevation and canopy condition on morphological traits and leaf fluctuating asymmetry of a bamboo, Chimonobambusa utilis in Jinfo Mountain Nature Reserve, Southwest China. Sains Malaysiana 43 (8): 1119-1125.

Liu Y, Yen T. 2021. Assessing aboveground carbon storage capacity in bamboo plantations with various species related to its affecting factors across Taiwan. For Ecol Manag 481: 118745. DOI: 10.1016/j.foreco.2020.118745.

Mera FAT, Xu C. 2014. Plantation management and bamboo resource economics in China. Cienc y Technol 879 (1): 1-12.

MoEF, FAO. 2007. National Forest and Tree Resources Assessment 2005-2007, Bangladesh. MoEF \& FAO, Dhaka.
Mulatu Y, Fetene M. 2013. The effect o,f silvicultural management on regeneration, growth and yield of Arundinaria alpina (Highland Bamboo) at Choke Mountain, East Gojam, Northwest Ethiopia. Ethiop J Agric Sci 27 (July): 11-27.

Muñoz-lópez J, Camargo-garcía JC, Romero-Ladino C. 2021. Valuation of ecosystem services of guadua bamboo (Guadua angustifolia) forest in the Southwestern of Pereira, Colombia. Caldasia 43 (10): 186-96. DOI: $10.1016 / J$.Foreco.2020.118745.

Ni H, Su W, Fan S, Chu H. 2021. Effects of intensive management practices on rhizosphere soil properties, root growth, and nutrient uptake in moso bamboo plantations in subtropical China. For Ecol Manag 493 (119083): 1-11. DOI: 10.1016/j.foreco.2021.119083.

Nirmala C, Bisht MS, Laishram M. 2014. Bioactive compounds in bamboo shoots: health benefits and prospects for developing functional foods. Intl J Food Sci Technol 49 (6): 1425-31. DOI: $10.1111 /$ ijfs. 12470

Nurhazwani O, Jawaid M, Paridah T, Juliana AH. 2016. Hybrid particleboard made from bamboo. Bioresources 11 (1): 306-323.

Partasasmita R, An'Amillah A, Iskandar J, Mutaqin AZ, Ratningsih N. 2017. Karangwangi people' s local knowledge of bamboo and its role: implications for management of cultural keystone species. Biodiversitas 18 (1): 275-82. DOI: 10.13057/biodiv/d180136.

Ramakrishnan M, Zhou M, Baskar K, Packiam S. 2018. Role of Bamboo in Ecosystem. Austin J Env Toxicol 4 (1): 1-2.

Raveendran VP, Jijeesh CM, Seethalakshmi KK. 2010. Effect of variation in clump density on the performance of reed bamboo (Ochlandra travancorica Benth) effect of variation in clump density on the performance of reed bamboo (Ochlandra travancorica Benth.). Proceedings of 22nd Kerala Science Congress, India.

Singh L, Sridharan S, Thul ST, Kokate P, Kumar P, Kumar S, Kumar R. 2020. Eco-rejuvenation of degraded land by microbe-assisted bamboo plantation. Ind Crops Prod 155: 112795. DOI: 10.1016/j.indcrop.2020.112795

Soejono, Budiharta S, Arisoesilaningsih E. 2013. Proposing local trees diversity for rehabilitation of degraded lowland areas surrounding springs. Biodiversitas 14 (1): 37-42. DOI: 10.13057/biodiv/d140106.

Somboon K. 2001. Review of Bamboo Management: Promotion of the Utilization of Bamboo from Sustainable Sources In Thailand, PD 56/99 Rev. L(I). Technical Report No.1. ITTO and Royal Forest Department, Bangkok.

Spradley JP. 2007. Metode Etnografi. Tiara Wacana, Sleman

Srivaro S, Jakranod W. 2016. Comparison of physical and mechanical properties of Dendrocalamus asper Backer specimens with and without nodes. Eur J Wood Wood Prod 74 (6): 893-899. DOI: 10.1007/s00107-016-1048-8.

Suryadi H, Harmita, Akbar MH, Lestari P. 2019. Characterization of hydroxypropyl cellulose produced from $\alpha$-cellulose betung bamboo (Dendrocalamus asper) and It's Application in Tablet Formulation. $\begin{array}{llllll}\text { Intl J Appl Pharm } 11 & \text { (2): 123-29. DOI: }\end{array}$ 10.22159/ijap.2019v11i2.31078.

Tajudin N, Ya'acob N, Ali DM, Adnan NA. 2021. Soil moisture index estimation from Landsat 8 images for prediction and monitoring landslide occurrences in Ulu Kelang, Selangor, Malaysia. Intl J Electr Comput Eng 11 (3): 2101-8. DOI: 10.11591/ijece.v11i3.pp21012108 .

Toledo-Bruno AG, Marin RA, Medina MAP, Puno GR, Villarta RO, Punoz RR. 2017. Ecology of litterfall production of giant bamboo Dendrocalamus asper in a watershed area. Glob J Environ Sci Manag 3 (4): 363-72. DOI: 10.22034/gjesm.2017.03.04.003.

Widodo TD, Raharjo R, Bintarto R, Pramudia M, Sunardi, Mamungkas MI, Wahudiono A. 2019. Effect of alkalization treatment on the tensile strength and interface character matrix-fibber of bamboo petung (Dendrocalamus asper) reinforced polyester resin composite. IOP Conf Ser Mater Sci Eng 494: 012081 DOI: 10.1088/1757899X/494/1/012081.

Xie J, Qi J, Hu H, De Hoop CF, Xiao H, Chen Y, Hse C. 2019. Effect of fertilization on anatomical and physical-mechanical properties of Neosinocalamus affinis bamboo. J Bioresour Bioprod 4 (1): 67-72. DOI: $10.21967 /$ jbb.v4i1.183.

Xu QF, Liang CF, Chen JH, Li YC, Qin H, Fuhrmann JJ. 2020. Rapid bamboo invasion (expansion) and its effects on biodiversity and soil processes. Glob Ecol Conserv 21: e00787. DOI: 10.1016/j.gecco.2019.e00787.

Yen TM. 2016. Culm height development, biomass accumulation and carbon storage in an initial growth stage for a fast-growing moso 
bamboo (Phyllostachys pubescens). Bot Stud 57 DOI: 10.1186/s40529-016-0126-x.

Yeny I, Yuniati D, Khotimah H. 2016. Local wisdom and practice of bamboo forest management in Bali community. J Penelitian Sosia dan Ekonomi Kehutanan 13 (1): 63-72. DOI 10.20886/jsek.2016.13.1.63-72.
Yuen JQ, Fung T, Ziegler AD. 2017. Carbon stocks in bamboo ecosystems worldwide: estimates and uncertainties. For Ecol Manag 393: 113-38. DOI: 10.1016/j.foreco.2017.01.017.

Zulkarnaen RN, Andila PS. 2015. Dendrocalamus spp.: Giant bamboo of Bogor Botanic Garden collections. Pros Sem Nas Masy Biodiv Indon 1: 534-538. DOI: 10.13057/psnmbi/m010326. [Indonesian] 